\title{
The Economic Theory of Utility Applied to a Web-Based Search for a Romantic Partner
}

\author{
Edmund H. Mantell \\ Professor of Economics and Finance \\ Lubin School of Business, Pace University, New York, N.Y.
}

\begin{abstract}
There are a few published studies that address the actual behavior of people in scenarios where the subjects must conduct searches of the kind typical of online dating sites. The consensus of the empirical findings seems to be that people tend to stop searching too soon. On the other hand, a very common psychological attitude among those who use online dating sites is a refusal to "settle" for anything less than their ideal partner, or someone very close to it. This paper addresses the question of how a man or a woman should apply the criterion of economic efficiency to choosing a person to pursue for a romantic relationship. The paper applies the mathematical theory of optimal stopping to a situation where a user of a dating website has identified a finite but perhaps very large sample of persons who are potential romantic partners. The paper applies the economic theory of a consumer's utility function to establish a stopping rule which maximizes the likelihood that the searcher will meet the candidate who maximizes the searcher's idiosyncratic attitudes.
\end{abstract}

KeyWords: Utility maximization, Internet dating, Application of optimal-stopping rules, Efficient criterion for choosing

[A man should marry] first, for virtue; secondly, for wit; thirdly, for beauty; and fourthly, for money. Samuel Johnson, LLD

\section{INTRODUCTION}

The proliferation of dating websites is evidence of consumer demand for personal relationships, even if initiating them requires payment to a third-party matchmaker. The expansion of Internet dating can be seen as a response to the defects of the traditional market mechanism. Ariely [1, p. 215] has commented that the dating market for single people (the coordination mechanism that helps them find partners efficiently) has long been "one of the most egregious market failures in Western society." This paper develops a theoretical analysis of the psychology of rational users of dating websites.

The introductory paragraph in a recent paper by Hitsch et al. [13] describes a few of the macromarket statistics characterizing the population of dating-site users. That paper carried out an ingeniously conceived empirical study of the efficiency of online dating. Using a novel dataset obtained from a major online dating service, the authors applied the Gale-Shapely algorithm to predict stable matches. They concluded, inter alia, that the predicted matches were similar to the actual matches achieved by the dating site, and that the actual matches were achieved efficiently. However, the definition of "efficient" employed by those authors was based on their finding that "... the observed and predicted attribute correlations and differences are largely similar [, which] suggests that the online dating market achieves an approximately efficient matching within the class of stable matches." I construe that statement to mean that users of 
online dating sites are generally successful in finding potential matches who display the reciprocating personal attributes that both parties are seeking.

The Hitsch paper does not address a question of economic efficiency confronting virtually all users of online dating sites, namely, the individual user's efficient allocation of the time he or she devotes to online searching for a potential partner. The salience of this question was vividly expressed by a recent essay appearing in the popular press.

Online dating generates a spectrum of reactions: exhilaration, fatigue, inspiration, fury....The typical American spends more of her life single than married, which means she's likely to invest even more time searching for romance online. Is there a way to do it more effectively, with less stress?

The importance of conducting a search efficiently is recognized by many users of online dating sites as well as by academics who study the socio-economics of online dating. The theory developed in this paper is new insofar as it addresses the question of how a searcher with a well-defined utility function can maximize the likelihood that he or she will choose the best from among a finite sample of candidates.

\section{THE HUSBAND SITE: A PARABLE OF THE PSYCHOLOGY OF SEARCHING THE INTERNET FOR A PARTNER}

In The Paradox of Choice, Schwartz [16] suggests that there is a point at which choice-the defining characteristic of individual freedom and self-determination-becomes detrimental to our psychological and emotional well-being. Gottlieb's book [11, p. 150] expresses the logic of a woman's perspective:

'It's like women who say, 'I've waited this long for Mr. Right, I'm not going to settle now.' The longer you wait and the more you search, the 'better' the guy is going to have to be. You don't want to have gone through all that struggle and turmoil only to end up with a 'good enough' guy just like the one you could have had and enjoyed years earlier. Which is all the more reason to choose the good enough guy the first time around."

The lesson to be learned from the comments reproduced above can be illustrated by a parable. A fantastic dating site comes online. It is called the Husband Site. Its target clientele is the population of single women who are looking for husbands. When a woman visits the site for the first time, the introductory webpage (i.e. the first page she sees) displays the terms-of-use imposed on all users of the site:

You may use the site to shop for a husband, but you may use it only once. The site displays five web pages in numerical order. If you enter the site you must visit the pages in ascending numerical order. Each numbered page displays photographs as well as information about each man in a sample of potential husbands. The attributes of the potential husbands in the sample are increasingly attractive in sequential pages. The shopper may select a husband from the sample displayed on any page and conclude her shopping, or she may click on the next numbered page. The site will not permit the shopper to revisit a page after she has clicked on a subsequently numbered page.

A hopeful woman enters the site and clicks on page 1.

Page 1. The banner heading on page 1 states: THIS PAGE DISPLAYS POTENTIAL HUSBANDS WHO ARE EMPLOYED FULL-TIME IN RESPECTABLE JOBS. The remainder of the page displays 
photographs the candidates, but no more information is displayed. The woman is favorably impressed by what she sees, but she is far from completely satisfied. She clicks on page 2 .

Page 2. The banner heading on page 2 states: THIS PAGE DISPLAYS POTENTIAL HUSBANDS WHO ARE EMPLOYED FULL-TIME IN RESPECTABLE JOBS AND WHO WOULD BE WONDERFUL FATHERS. The woman likes the potential husbands displayed on page 2, but she does not like any of them enough to stop her search on that page. She clicks on page 3.

Page 3. The banner heading on page 3 states: THIS PAGE DISPLAYS POTENTIAL HUSBANDS WHO ARE EMPLOYED FULL-TIME IN RESPECTABLE JOBS, WOULD BE WONDERFUL FATHERS AND WILL HELP EQUALLY WITH THE HOUSEWORK. The woman is very encouraged by the attributes of the husband candidates on page 3 and she wonders how much better she can do. She clicks on page 4 .

Page 4. The banner heading on page 4 states: THIS PAGE DISPLAYS POTENTIAL HUSBANDS WHO ARE EMPLOYED FULL-TIME IN RESPECTABLE JOBS, WOULD BE WONDERFUL FATHERS, WILL HELP EQUALLY WITH THE HOUSEWORK, AND ARE SENSITIVE TO A WOMAN'S FEELINGS AND NEEDS. The woman is thrilled by the men in the sample on page 4. She thinks: "This is the kind of husband I'm looking for." She is tempted to make her selection from the sample on this page, but she entertains a nagging doubt. She thinks: "There are a few other attributes I'd really like in a husband and I'm a wonderful catch for any man. I deserve better. Maybe I can do better if I don't settle for any of the husbands on this page." She clicks on page 5.

Page 5. The banner heading on page 5 states: YOU ARE VISITOR 139,473,201 TO THIS PAGE. THERE ARE NO POTENTIAL HUSBANDS DISPLAYED ON THIS PAGE. THIS PAGE APPEARS ON THE SITE ONLY TO PROVE THAT THE WOMEN CLICKING ON THIS PAGE, INCLUDING YOU, DO NOT KNOW HOW TO CONDUCT AN EFFICIENT SEARCH FOR A SATISFACTORY HUSBAND. THANK YOU FOR VISITING THE HUSBAND SITE.

The parable exemplifies the problem faced by all people who use online websites to search for a partner. Search is costly and produces a sequence of potential partners of varying quality. Rejecting current opportunities means the prospect of a better match later, but it also means continued search costs (mainly time) and the implicit risk of failing to locate a match superior to those who have been discarded.

The searcher in the fantasy parable is a woman, but the teaching applies equally to men. The parable is designed to illustrate the likely consequence of failing to recognize when one should stop the search and actively pursue a specific candidate. The next section addresses that question. The next section reverses the sex of the searcher and shows how an optimal stopping rule can be applied to maximize the probability of finding a good partner.

\section{SELECTING THE BEST FROM AMONG THE CANDIDATES DISCOVERED IN THE WEB-BASED SEARCH.}

Suppose a man uses a web-based dating site to discover the profiles of $\mathrm{N}$ women that are potentially appealing to him. That is to say, the array of attributes displayed by the profile of each woman in his sample satisfies the minimal criterion of the man's utility function. 
After having found a (possibly large) sample of candidates for a potential relationship with him, the man recognizes his second problem: How can he select women from the sample to meet?

If the number of candidates is large, say, more than 100 women, it may be impractical (perhaps impossible) to meet all of them. The cost of meeting and interviewing each candidate is manifested as time, money, effort, and psychological stress. The aggregate value of these costs is prohibitive for a large sample of candidates.

The defining characteristics of the choice problem faced by the man are as follows:

1. The man wants identify and pursue the "best" woman (whatever that may mean to him) among the $\mathrm{N}$ candidates his search has discovered.

2. The women, if he were to meet and interview them all, can be ranked by the man's utility function from best to worst, with no ties.

3. The women are met and interviewed sequentially in random order, with each order being equally likely.

4. Immediately after meeting and interviewing each woman, the man makes an irrevocable decision to engage with that woman or to dismiss her.

5. The man's decision to engage or dismiss is based exclusively on the ordinal utility rankings of the women he met previously.

These five characteristics constitute a formulation addressed by a famous problem in optimalstopping theory. An application of the theory is described below.

\section{The stopping rule for finding the "best" woman in the sample.}

The application of optimal-stopping is theory to maximize the probability that the specific woman selected by the man for further engagement is the woman who generates the maximum utility for him among the candidates his search has discovered.

Under the protocol of an optimal-stopping rule, the man selects a fixed parameter $\mathrm{k}$, a nonnegative integer. The man meets a series of $\mathrm{k}-1$ randomly selected candidates in the sample of the women his search discovered. The operation of the stopping rule requires the man to dismiss the first $\mathrm{k}-1$ of the women he meets. Let $\mathrm{M}$ represent the maximum utility among the $\mathrm{k}-1$ women the man has met and dismissed. The man selects for further engagement the first woman he meets subsequently who generates a utility exceeding M.

The rational basis for this strategy is reasonably clear: (a) It takes full advantage of the information as to the utility yielded by each woman in the sample he has met and (b) It acknowledges the uncertain utility of the women in the sample he has not yet met.

This stopping problem has a solution for the optimal value of $\mathrm{k}$ for large $\mathrm{N}$. The optimalstopping rule prescribes dismissal of the first N/e women the man meets. He should then engage the next woman who generates a utility exceeding any of the previously dismissed women (or continuing to the last woman in the sample if this never occurs). Sometimes this is called the 1/e stopping rule because the probability of stopping the search at the woman generating the maximum utility is about $1 / \mathrm{e}$ for any large value of $\mathrm{N}$.

One reason the rule may be appealing to online searchers is that the stopping rule is simple to apply and it selects the "best" candidate about 37 percent of the time, regardless of whether 
there are 100 or 100 million candidates in the sample; $1 / \mathrm{e} \approx 0.368$. For online daters who have suffered many disappointing first dates, these might seem like pretty good odds.

\section{Illustrative application of the optimal-stopping rule for a small number of impressions}

For a relatively small number of candidates in the sample, say fewer than six, the optimalstopping parameter $\mathrm{k}$ can be obtained by simply counting the permutations of the randomly ordered conversions. I illustrate a simple application of the rule below.

Suppose a man discovers a sample of four women of varying appeal, i.e. $N=4$. Each woman is the embodiment of one of the attributes appearing in the epigraph to this paper, but she is only modestly endowed with the other three attributes. The man's utility function is symbolized by $\mathrm{U}$ (attribute). the utility generated by each of the four candidates is represented below.

One of the women has a large income, but her other attributes are not especially appealing to the man. She is symbolized by $\mathrm{I} ; \mathrm{U}(\mathrm{I})=1$.

One of the women is considered by the man to be extraordinarily beautiful, but her other attributes are not especially appealing to him. She symbolized by B; U(B) $=2$

One of the women is very witty and charming, but her other attributes are not especially appealing to the man. She is symbolized by $W ; U(W)=3$

One of the women is conspicuously virtuous, but her other attributes are not especially appealing to the man. She is symbolized by $V ; U(V)=4$

Until the man actually meets the women he cannot match up each woman with the utility she generates. At the hypothetical face-to-face meeting with each woman the man's utility function assigns the values displayed above. For example, if the man meets and interviews the beautiful woman he will infer that she embodies few or none of the other attributes he seeks. After meeting her, his utility function assigns a value of 2 . The man knows that if he meets all four of the women, they can be ranked by his utility function from worst to best.

The man can calculate the probability of meeting the "best" woman in a randomized draw from the sample his search has discovered. He recognizes that if he meets the women randomly, there are 24 possible permutations of sequential meetings. The array below displays every possible ordering of the utilities generated by sequential meetings.

$$
\begin{array}{llll}
1,2,3,4 & 2,1,3,4 & 3,1,2,4 & 4,1,2,3 \\
1,2,4,3 & 2,1,4,3 & 3,1,4,2 & 4,1,3,2 \\
1,3,2,4 & 2,3,1,4 & 3,2,1,4 & 4,2,1,3 \\
1,3,4,2 & 2,3,4,1 & 3,2,4,1 & 4,2,3,1 \\
1,4,2,3 & 2,4,1,3 & 3,4,1,2 & 4,3,1,2 \\
1,4,3,2 & 2,4,3,1 & 3,4,2,1 & 4,3,2,1
\end{array}
$$

To explain: The set of utilities $[2,4,1,3]$ signifies a sequence where the man meets the wittiest woman first, the most virtuous of the women second, the woman with the largest income third, and the most beautiful of the women fourth. The utilities generated by this specific order of conversions are: $\mathrm{U}(\mathrm{W})=2, \mathrm{U}(\mathrm{V})=4, \mathrm{U}(\mathrm{I})=1, \mathrm{U}(\mathrm{B})=3$. 
If the man had met the women in the order identified above, his last meeting would not have produced the optimal result. He would have optimized his search if he had stopped after the second meeting instead of pressing on. Since all the permutations are assumed to be equally likely, the man should apply an efficient algorithm for stopping his search.

In this simple case, the application of the optimal-stopping rule requires the man to select an integer value for $\mathrm{k}$ between 1 and 4 . Then, after having met and dismissed $\mathrm{k}-1$ candidates, he should actively engage with the first woman who generates a larger utility than any of the previously dismissed women. The consequences of the application of this rule for different values of $\mathrm{k}$ are shown below. The conditional probability that the application of the optimalstopping rule in this scenario will find the woman with the maximum utility, given $\mathrm{k}=\mathrm{i}$, is symbolized as: $\operatorname{Prob}\left[\max \left\{U_{i}\right\} \mid k=i\right] i=1,2,3,4$.

$$
\boldsymbol{k}=\mathbf{1}
$$

When $k=1$ the optimal-stopping rule requires the man to select a woman at random for further engagement and dismisses all the others. There are six permutations where the maximum-utility woman is randomly selected. These are listed below.

$\{4,1,2,3\}\{4,1,3,2\}\{4,2,1,3\}\{4,2,3,1\}\{4,3,1,2\}\{4,3,2,1\}$

Thus $\operatorname{Prob}\left[\max \left\{U_{i}\right\} \mid k=1\right]=\frac{6}{24}=.25$.

$$
\boldsymbol{k}=\mathbf{2}
$$

When $k=2$ the optimal-stopping rule requires the man to assess the utility of a randomly selected woman and to dismiss her. He then continues meeting the women (selecting them randomly) and stops at the first woman whose utility exceeds that of the dismissed woman. The array shows that there are 11 equally likely permutations where the stopping rule will generate the utility-maximizing meeting. These are listed below.

$\{1,4,2,3\}\{1,4,3,2\}\{2,4,1,3\}\{2,4,3,1\}\{2,1,4,3\}\{3,4,1,2\}\{3,4,2,1\}\{2,1,4,3\}\{3,2,1,4\} \quad\{3,1,4,2\}$ $\{3,1,2,4\}$

Thus, $\operatorname{Prob}\left[\max \left\{U_{i}\right\} \mid k=2\right]=\frac{11}{24}=.458$.

$$
\boldsymbol{k}=\mathbf{3}
$$

When $k=3$ the optimal-stopping rule requires the man to assess the utility of two randomly selected women after meeting them and dismiss them both. He then continues his meetings and stops at the first woman whose utility exceeds that of both of the dismissed women. The array shows that there are 10 permutations of meetings where the stopping rule will generate the utility-maximizing meeting. These are listed below.

$$
\begin{aligned}
& \{1,2,4,3\} \quad\{1,3,2,4\}\{1,3,4,2\}\{2,1,4,3\} \quad\{2,3,1,4\} \quad\{2,3,4,1\} \quad\{3,1,2,4\} \quad\{3,1,4,2\} \quad\{3,2,1,4\} \quad\{3,2,4,1\} \\
& \text { Thus, } \operatorname{Prob}\left[\max \left\{U_{i}\right\} \mid k=3\right]=\frac{10}{24}=.417
\end{aligned}
$$

$$
\boldsymbol{k}=\mathbf{4}
$$


When $k=4$ the optimal-stopping rule requires the man to assess the utility of three randomly selected women and dismiss them all. He then meets and stops his search at the fourth woman. The array shows that there are six permutations of four meetings such that the last of them is the woman who generates the man's maximum utility. These are listed below.

$\{1,2,3,4\}\{1,3,2,4\}\{2,1,3,4\}\{2,3,1,4\}\{3,1,2,4\}\{3,2,1,4\}$

Thus, $\operatorname{Prob}\left[\max \left\{U_{i}\right\} \mid k=4\right]=\frac{6}{24}=.25$.

Evidently, if the man's search discovers four appealing women, he will maximize the probability of engaging the best of them (in this scenario, the most virtuous of the women) if he applies a stopping-rule parameter equal to two.

It is obvious that counting permutations by examination rapidly becomes impractical as the number of candidates in the sample increases. However, the problem can be solved by standard methods of dynamic programming. TABLE 1 below displays the optimal-stopping parameters for samples of different sizes.

TABLE 1

\section{CONSEQUENCES OF APPLYING THE STOPPING RULE FOR DIFFERENT SAMPLE SIZES}

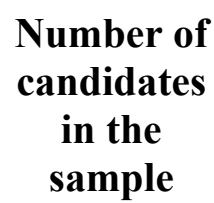

1

2

3

4

5

6

7

8

9

10

$\begin{array}{cc}\text { Optimal } & \begin{array}{c}\text { Conditional } \\ \text { probability } \\ \text { of finding } \\ \text { the best } \\ \text { parameter } \\ \text { candidate }\end{array} \\ 1 & 100.0 \% \\ 1 & 50.0 \% \\ 2 & 50.0 \% \\ 2 & 45.8 \% \\ 3 & 43.3 \% \\ 3 & 42.8 \% \\ 3 & 41.4 \% \\ 4 & 41.0 \% \\ 4 & 40.6 \% \\ 4 & 40.1 \%\end{array}$

As the number of candidates in the sample increases without limit, the probability of selecting the "best" of them converges to 1 /e.

\section{EXPERIMENTAL FINDINGS AND THE LIMITS OF THE EXPLANATORY POWER OF THE STOPPING THEORY}

There are a few published studies that address the actual behavior of people in scenarios where the subjects must conduct searches of the kind typical of online dating sites. The consensus of the empirical findings seems to be that people tend to stop searching too soon.

In the real world of online dating, the empirical finding might be a consequence of the fact that people do not search enough when they are in situations where their decision alternatives are 
presented sequentially. People may be accustomed to deciding among alternatives in situations where all their alternatives are displayed concurrently.

If the experimental finding is representative of online dating behavior, it may reflect, at least in part, the costs of meeting. The activity of meeting may be very costly to both parties in terms of time, money, and the psychological stress to appear personally attractive when participating in a face-to-face meeting. None of these costs are comprehended in the theory of this paper.

\section{CONCLUDING REMARKS}

The theory applied in this paper suggests how a person searching for a romantic partner can apply a rule to limit his or her choices among a fixed pool of candidates. The advice offered by a self-described professional dating coach is relevant to the question of when to stop searching for the "best" partner. In the book by Gottlieb [11, p. 75], the author explains to a female professional dating coach her attitude about conducting her search for a man to marry after she reached her 40th birthday:

[Older people] tend to be more jaded. They're not as hopeful and appealing as younger single people tend to be. I told [the dating coach] that I didn't consider these factors when I was 10 years younger and waiting for just the right guy to pop into my life. It seemed reasonable to think that the longer I searched, the better the guy I'd come up with. But it's faulty logic [the dating coach said]: The longer you wait, the less likely you are to find someone better than you've already met.

The last sentence in the paragraph quoted above nicely captures the optimal property of optimal-stopping rules.

\section{APPENDIX}

For a finite and fixed sample of candidates of size $\mathrm{N}$, and an arbitrary stopping integer $\mathrm{k}$, the probability that the best of the candidates is selected when the search is stopped at $\mathrm{k}$ can be expressed as:

$$
P(k)=\sum_{i=1}^{N} P(\text { candidate } i \text { is chosen } \cap \text { candidate } i \text { is the best })
$$

The probability expression in A1 can be decomposed into a sum of conditional probabilities.

$$
P(k)=\sum_{i=1}^{N} P(\text { candidate } i \text { is chosen } \mid i \text { is the best }) P(\text { candidate } i \text { is the best }) \quad A 2
$$

It is obvious that the unconditional probability that an arbitrary candidate is the best is simply $\frac{1}{N}$. Thus, the sum of the probabilities in A2 can be rewritten as:

$$
P(k)=\frac{1}{N} \sum_{i=1}^{N} P(\text { candidate } i \text { is chosen } \mid \text { candidate } i \text { is the best })
$$

Expression A3 can be partitioned into two partial sums: one partition is the sum of the first $k-1$ terms in A3 and the remaining partial sum is the complement:

Where

$$
P(k)=\frac{1}{N}\left(S_{k-1}+S_{N}\right)
$$




$$
S_{k-1}=\sum_{i=1}^{k-1} P(\text { candidate } i \text { is chosen } \mid \text { candidate } i \text { is the best })
$$

And

$$
S_{N}=\sum_{i=k}^{N} P(\text { candidate } i \text { is chosen } \mid \text { candidate } i \text { is the best })
$$

Inasmuch as the stopping rule requires the searcher to dismiss the first $k-1$ candidates, the probability that any of them is chosen is zero. Thus one can write:

$$
S_{k-1}=0
$$

The remaining partition, $S_{N}$ in A5 can be expressed as:

$$
P(k)=\frac{1}{N} \sum_{i=k}^{N} P[\text { the best of the first } i-1 \text { is in the first } k-1 \mid i \text { is the best }] \quad A 7
$$

The partial sum in A7 can be calculated by observing that if candidate i is the best candidate, then she will be chosen if and only if the best candidate among the first i-1 candidates is among the first $k-1$ candidates that were dismissed. This reasoning allows the expression in A7 to be calculated as:

$$
P(k)=\frac{1}{N} \sum_{i=k}^{N} \frac{k-1}{i-1}=\frac{k-1}{N} \sum_{i=k}^{N} \frac{1}{i-1}
$$

The sum in A8 is not defined for a value of $i=k=1$. However, if $k=1$ the searcher will not meet any of the candidates; He will simply choose to engage with a randomly selected candidate. In this scenario the probability that a randomly chosen candidate is the best in the sample is obviously $\frac{1}{N}$.

For large values of $\mathrm{N}$ tending to infinity, the sum in $\mathrm{A} 8$ can be approximated by a definite integral.

Let $x=\lim \frac{k}{N}$

Let $y=\frac{i}{N}$ and $d y=\frac{1}{N}$

Substituting the values into expression A6, it can be approximated by the integral:

$$
P(x)=x \int_{x}^{1} \frac{1}{y} d y=-x \ln x
$$

The value of $\mathrm{k}$ that maximizes the probability of choosing the best of the candidates to engage corresponds to the value of $x$ that maximizes $P(x)$ in A8. The usual maximization algorithm for continuous functions applies: calculate the derivative of $P(x)$ in A7 w.r.t. $\mathrm{x}$ and solve $P^{\prime}(x)=0$ for $x$.. The solution value for $x$. is $\frac{1}{e}$. Thus, as the sample size $\mathrm{N}$ increases, the optimal stopping rule approaches $\frac{N}{e}$. For a large sample of candidates, the probability that the optimal stopping rule will select the best of them is $\frac{1}{e}$. 


\section{Reference List}

1. Ariely, Dan. (2010) The Upside of Irrationality. New York, N.Y., Harper Collins

2. Ansari, Aziz, and Eric Klinenberg. (2015) How to Make Online Dating Work. The New York Times, June 4, 2015, the Sunday Review, p. 6.

3. Bearden, J.N. (2006) A New Secretary Problem with Rank-based Selection and Cardinal Payoffs. Journal of Mathematical Psychology. 50, PP. 58-9. doi: 10.1016/j.jmp. .11.003

4. Bearden, J.N., R. O.Murphy, and A. Rapoport. (2005) A Multi-Attribute Extension of the Secretary Problem. Journal of Mathematical Psychology. 49 (5), pp.410-425, doi:10.1016/j.jmp.2005.08.002.

5. Bearden, J.N., A. Rapoport, and R. O. Murphy. (2006) Sequential Observation and Selection with Rankdependent Payoffs: An Experimental Test. Management Science. 52 (9): pp. 1437-49. doi: $10.1287 /$ mnsc. 1060.0535 .

6. Bruss, F. Thomas. (1984) A Unified Approach to a Class of Best Choice Problems with an Unknown Number of Options. Annals of Probability. 12 (3): 882-891. doi:10.1214/aop/1176993237

7. Chow, Y.S., Robbins, H. and Siegmund, D. (1971) Great Expectations: The Theory of Optimal Stopping. Boston: Houghton Mifflin.

8. Coleman, Linda Jane, and Nisreen Bahnan. (2009) Segmentation Practices of e-Dating, Chapter XIV in Social Networking Communities and E-Dating Services. Romm-Livermore and Setzekorn (eds.) Information Science Reference, IGI Global, New York.

9. Ferguson, T. S. (1989). Who solved the secretary problem? Statistical Science. 4 (3): 282-296. doi:10.1214/ss/1177012493.

10. Ghirdar, Y., Dudek G. (2009). Optimal Online Data Sampling or How to Hire the Best Secretaries. Proc. Computer and Robot Vision: 292-298. doi:10.1109/CRV.2009.30.

11. Gottlieb, Lori. (2010) Marry Him-The Case for Settling for Mr. Good Enough. New York, Dutton.

12. Hawkins, Sir John. Johnsonia; or, Supplement to Boswell: Being Anecdotes and Sayings of Dr. Johnson. J. Wilson Croker (ed.), Carey and Hart, Philadelphia, 1842.

13. Hitsh, Günter J., Ali Hortaçsu, and Dan Ariely. (2010) Matching and Sorting in Online Dating. American Economic Review. 100:1, 130-163

14. Kale, Sudhir, and Mark T. Spence. (2009) A Trinational Analysis of Social Exchange Relationships in EDating. Chapter XVIII in Social Networking Communities and E-Dating Services. Romm-Livermore and Setzekorn (eds.) Information Science Reference, IGI Global, New York.

15. Seale, D. A., and A. Rapoport. (1997) Sequential Decision-making with Relative Ranks: an Experimental Investigation of the Secretary Problem. Organizational Behavior and Human Decisions Processes 69(3), pp. 221-236. doi: 10.1006/obhd.1997.2683

16. Schwartz, Barry. (2005) The Paradox of Choice: Why More Is Less. New York, Harper Perennial.

17. Whitty, Monica. (2009) E-DATING: The Five Phases of Online Dating, Chapter XVI in Social Networking Communities and E-Dating Services. Romm-Livermore and Setzekorn (eds.) New York, Information Science Reference, IGI Global. 